\title{
ELABORAÇÃO DE SUCO MISTO DE FRUTAS COM POTENCIAL FUNCIONAL E COMPARAÇÃO COM SUCO COMERCIAL "DETOX"
}

\author{
P. G. MACHADO ${ }^{1}$, C. SPERONI ${ }^{2}$, J. F. FERRAZ ${ }^{2}$, P. D. FIGLESKI ${ }^{2}$, R. H. KOCH ${ }^{2}$, J. SEVERO ${ }^{2}$ \\ ${ }^{1}$ Universidade do Estado de Santa Catarina, Pinhalzinho \\ ${ }^{2}$ Instituto Federal Farroupilha, Campus Santo Augusto \\ E-mail para contato: paatriciamachado@gmail.com
}

\begin{abstract}
RESUMO - A procura por alimentos saudáveis tem crescido consideravelmente em um cenário em que os alimentos que apresentem propriedades funcionais têm ganhado destaque. Dessa forma, o objetivo do presente estudo foi elaborar um suco misto de frutas e comparar com um suco comercial que apresenta a denominação de "Detox" no rótulo. Foram realizadas análises de sólidos solúveis totais e acidez total titulável, além dos teores de compostos fenólicos totais, carotenoides totais e atividade antioxidante do suco elaborado nesse trabalho, denominado "Suco-IFFar", e de suco comercial que apresenta a denominação de "Detox". Testes de análise sensorial indicaram que o "Suco-IFFar" apresentou boa aceitabilidade, intenção de compra e foi preferido em relação ao comercial. Apesar do "Suco-IFFar" apresentar teores de compostos fenólicos totais e carotenoides totais superiores ao suco comercial, a atividade antioxidante foi inferior no "Suco-IFFar".
\end{abstract}

Palavras-chave: antioxidante, carotenoides, fenólicos, aceitabilidade

DOI: $10.5965 / 24473650312017002$

\section{INTRODUÇÃO}

O desenvolvimento de alimentos funcionais tem aumentado nas últimas décadas, como resultado da conscientização dos consumidores de que a melhoria da qualidade de vida está relacionada com a boa alimentação. A conhecida correlação entre dieta e efeitos fisiológicos no organismo humano tem gerado ótimas possibilidades para a indústria alimentícia promover seus produtos juntamente com a saúde dos consumidores. Assim, o desenvolvimento de novos alimentos funcionais tem-se centrado principalmente na composição nutricional dos alimentos e não somente nas suas características organolépticas (SILVA, et al., 2016).

O termo alimentos funcionais surgiu no Japão na década de 80 devido a um programa de governo que tinha como objetivo desenvolver alimentos saudáveis (MORAES, COLA, 2006). A legislação brasileira, através da portaria n 398 de 1999, define alimentos funcionais como sendo "todo aquele alimento ou ingrediente que, além das funções nutricionais básicas, quando consumido como parte da dieta usual, produz efeitos metabólicos e/ou físiológicos 
e/ou efeitos benéficos à saúde, devendo ser seguro para consumo sem supervisão médica" (BRASIL, 1999).

Um alimento pode ser considerado funcional se for demonstrado que o mesmo possui efeito benéfico na fisiologia humana, além da nutrição básica, de maneira que seja tanto relevante para a nutrição quanto para a redução do risco de uma doença. $\mathrm{O}$ efeito benéfico à saúde é resultante da presença de diferentes componentes, como probióticos, prebióticos, compostos derivados do metabolismo secundário vegetal, como carotenoides e compostos fenólicos, fibras, vitaminas lipossolúveis e hidrossolúveis, oligoelementos, enzimas antioxidantes, entre outros (ROBERFROID, 2002; MORAES, COLA, 2006; COSTA, ROSA, 2010; SILVA, et al., 2016).

Frutas e hortaliças apresentam uma grande variedade de compostos de origem fenólica, terpênica, vitaminas e sais minerais, além de fibras que estão presentes nesses alimentos (COSTA,ROSA, 2010; BVENURA, SIVAKUMAR, 2017). Os flavonoides compõem uma ampla classe de substâncias de origem fenólica, na qual estão incluídas as antocianinas, que são uma importante classe de pigmentos naturais encontrados com frequência na natureza. Tais compostos possuem uma série de propriedades farmacológicas que atuam sobre os sistemas biológicos (KIRAKOSYAN et al., 2010; SILVA, et al., 2016). Os carotenoides são pigmentos de origem terpênica que podem ser encontrados em frutas e vegetais com coloração variando do laranja ao vermelho, de acordo com o grupamento químico carotenoide predominante. $\mathrm{O}$ conteúdo de carotenoides das frutas aumenta durante o amadurecimento e a parte de intensificação da cor se deve a perda de clorofila (CHITARRA, CHITARRA, 1990). Os carotenoides atuam protegendo as estruturas lipídicas das membranas celulares. Seus principais representantes são os carotenos, precursores da vitamina A, e o licopeno (STAHL, SIES, 2003; COSTA; ROSA, 2010).

Antioxidantes naturais, presentes na dieta, aumentam a resistência a danos oxidativos decorrentes da ação de radicais livres que podem ocasionar sérios impactos na saúde humana (DIMITRIUS, 2006). Vários modos de ação têm sido propostos para explicar os efeitos benéficos dos compostos bioativos, incluindo ação antioxidante e anti-inflamatória, modulação da transcrição e expressão de genes, além da indução à apoptose e necrose (SILVA, et al., 2016). Dessa forma, estudos vêm relacionando o consumo de frutos com diversas doenças, devido à presença destes compostos (STAHL, SIES, 2003; SUN, LIU, 2006; MEDINA et al., 2011; BVENURA, SIVAKUMAR, 2017).

De acordo com o Decreto ${ }^{\circ} 6.871$ de 2009, que regulamenta a Lei n. 8918 de 1994, suco misto é o suco obtido pela mistura de frutas, combinação de fruta e vegetal, combinação das partes comestíveis de vegetais ou mistura de suco de fruta e vegetal, sendo a denominação constituída da expressão suco misto, seguida da relação de frutas ou vegetais utilizados, em ordem decrescente das quantidades presentes na mistura (BRASIL, 2009).

O objetivo do presente estudo foi elaborar um suco misto, denominado como "SucoIFFar", com potencial para alegação de propriedade funcional e/ou de saúde, devido às frutas e hortaliças utilizadas na sua formulação, comparando com uma versão comercial de suco misto que apresenta a denominação "Detox" no rótulo. 


\section{MATERIAIS E MÉTODOS}

Os ingredientes necessários para a elaboração do "Suco-IFFar", foram obtidos no comércio local do Município de Santo Augusto-RS, e encaminhados para o Laboratório de Tecnologia de Frutas e Hortaliças, do Instituto Federal Farroupilha (IFFar), Campus Santo Augusto.

Após a seleção das frutas, realizou-se a lavagem em água clorada 100 ppm e posterior enxague em água potável. As frutas foram descascadas manualmente, cortadas e trituradas com o auxílio de liquidificador. Após a trituração, os sucos obtidos foram então utilizados na elaboração do "Suco-IFFar".

Na elaboração do "Suco-IFFar", utilizou-se a seguinte formulação (v/v): $25 \%$ de suco de abacaxi cv. Pérola, 20\% de suco de cenoura cv. Brasília, (elaborado na proporção 1:2, cenoura:água), $15 \%$ de água de coco (Ducoco ${ }^{\circledR}$ ), 15\% de suco de maçã cv. Fuji, $10 \%$ de suco de couve folha (elaborado na proporção 1:2, couve:água), $10 \%$ de água potável, adicionado de $0,1 \%$ de gengibre $(\mathrm{p} / \mathrm{v}), 0,1 \%$ de hortelã $(\mathrm{p} / \mathrm{v})$ e $1 \%$ de frutose $(\mathrm{p} / \mathrm{v})$. A formulação do suco comercial "Detox" utilizada na comparação era composta por abacaxi, cenoura, maçã, couve, pepino, pêra e água de coco, não apresentando em sua embalagem as quantidades adicionadas destes ingredientes.

O teor de sólidos solúveis (SS), acidez titulável (AT), foram avaliados de acordo com as normas do Instituto Adolfo Lutz (IAL, 2008). O teor de carotenoides totais foi quantificado utilizando método espectrofotômetro proposto por Rodriguez-Amaya (2001). O teor de compostos fenólicos totais foi determinado por método espectrofotométrico sugerido por Singleton e Rossi (1965). A atividade antioxidante foi determinada com a utilização do radical ABTS (2,2-azino-bis-3-etilbenzotiazolin 6-ácido sulfônico), sendo os resultados expressos em $\mu \mathrm{g}$ TE $\mathrm{g}^{-1}$ (equivalente Trolox por grama de amostra) utilizando curva padrão com Trolox (6Hidroxi-2,5,7,8-tetrametilchroman-2-ácido carboxílico) de acordo com Re et al., (1999).

Para avaliação sensorial foram realizados os testes de aceitação e de intenção de compra, com 50 julgadores não treinados, além do teste de comparação pareada, com 30 julgadores não treinados. No teste de comparação pareada, foram fornecidas aos julgadores duas amostras codificadas apresentadas em ordem balanceada (A, B), onde o mesmo deveria identificar qual amostra era de sua preferência.

Já no teste de aceitação por escala hedônica, foi fornecida uma amostra aos julgadores onde o mesmo expressou o grau de gostar ou desgostar do "Suco-IFFar". Foi utilizada escala de 1 a 5 pontos, onde 1 representa desgostei muito já o ponto 5 gostei muito.

Para o teste de intenção de compra, foi fornecida uma amostra aos provadores, onde os mesmos deveriam expressar sua vontade de comprar o produto que lhe foi fornecido utilizando escala de 1 a 5 pontos, onde 1 representa (nunca compraria este produto) e o ponto 5 representa (sempre compraria).

Todas as análises foram realizadas em triplicata e as médias obtidas foram utilizadas para calcular o desvio padrão e submetidas, ao teste de Tukey a 5\% de significância. 


\section{RESULTADOS}

Apesar de não existir legislação para sucos denominados como "Detox", essa denominação aparece nos rótulos de sucos do País. Alguns componentes presentes nesses sucos apresentam potencial funcional comprovado, como é o caso de alguns carotenoides, flavonoides e vitaminas antioxidantes. No entanto, o uso dessa denominação "Detox" não está previsto na legislação vigente, o que provoca divisão na opinião pública sobre o seu uso.

Ainda não existe comprovação científica da ação do suco "Detox", o que existe é o conhecimento sobre a ação de alguns compostos que estão presentes nos sucos, que possuem comprovada funcionalidade.

Os resultados obtidos nas análises de SS, AT, carotenoides totais, compostos fenólicos totais e atividade antioxidante do "Suco-IFFar" e do suco comercial "Detox" estão descritas na Tabela 1.

Tabela 1 - Caracterização de suco comercial "Detox" e de suco misto elaborado "SucoIFFar"

\begin{tabular}{llllll}
\hline & $\begin{array}{l}\text { SS } \\
\left({ }^{\circ} \text { Brix }\right)\end{array}$ & $\begin{array}{l}\text { AT } \\
(\% \\
\text { cítrico })\end{array}$ & $\begin{array}{l}\text { Fenólicos } \\
\text { totais } \\
(\mathrm{mg} \\
\left.100 \mathrm{~g}^{-1}\right)\end{array}$ & $\begin{array}{l}\text { Carotenoides } \\
\text { totais } \\
(\mu \mathrm{g} \beta \text { caroteno } \\
\left.\mathrm{g}^{-1}\right)\end{array}$ & $\begin{array}{l}\text { Atividade } \\
\text { Antioxidante } \\
\left(\mu \mathrm{ET} \mathrm{E}^{-1}\right)\end{array}$ \\
\hline $\begin{array}{l}\text { Suco } \\
\text { comercial } \\
\text { "Detox" }\end{array}$ & $14,5 \pm 0,1 \mathrm{a}$ & $0,13 \pm 0,17 \mathrm{a}$ & $70,48 \pm 0,8 \mathrm{a}$ & $9,02 \pm 1,13 \mathrm{a}$ & $44,28 \pm 5,31 \mathrm{a}$ \\
$\begin{array}{l}\text { Suco misto } \\
\text { "Suco- }\end{array}$ & $8,0 \pm 0,1 \mathrm{~b}$ & $0,26 \pm 0,23 \mathrm{~b}$ & $81,38 \pm 5,10 \mathrm{~b}$ & $18,8 \pm 0,56 \mathrm{~b}$ & $40,54 \pm 0,81 \mathrm{~b}$ \\
\hline \begin{tabular}{l} 
IFFar" \\
\hline
\end{tabular}
\end{tabular}

SS: Sólidos solúveis. AT: Acidez total. EAG: equivalente ácido gálico. ET: equivalente Trolox. Média da triplicata \pm desvio padrão. Médias apresentadas na mesma coluna seguidas com letras diferentes diferem significativamente pelo teste de Tukey a $5 \%$.

Observou-se um teor superior de SS no suco comercial "Detox", em relação ao suco elaborado nesse trabalho (Tabela 1). O teor de sólidos solúveis é utilizado para medir a quantidade aproximada de açúcares, pois os açucares são os sólidos solúveis predominantes nas frutas. A preferencia apresentada pelo "Suco-IFFar", apesar do baixo teor de SS, pode estar relacionada com a adição da frutose na formulação, que possui poder adoçante superior à sacarose, açúcar comumente utilizado na elaboração de sucos e néctares (OETTERER et al., 2006).

O teor de AT foi superior no "Suco-IFFar" (Tabela 1). A acidez superior do "SucoIFFar", pode estar relacionada ao estádio de maturação dos frutos utilizado e também ao suco de limão adicionado na formulação, o qual não estava presente, de acordo com o rótulo, na formulação do comercial. A análise de acidez titulável determina a quantidade de ácido de 
uma amostra, na qual os ácidos orgânicos, em especial o ácido cítrico, influenciam o sabor, odor, cor e estabilidade de alimentos (OETTERER et al., 2006).

Os teores de compostos fenólicos totais foram superiores no "Suco-IFFar", em relação ao suco comercial "Detox", apresentando valores de $81,38 \mathrm{mgEAGg}^{-1}$ e 70,48 $\mathrm{mgEAGg}^{-1}$, respectivamente (Tabela 1). Os resultados obtidos nesse estudo para ambos os sucos avaliados são superiores ao relatado por Leone (2009), que em sua formulação de suco misto de frutas e hortaliças obteve $39,83 \mathrm{mgEAGg}^{-1}$.

Os teores de carotenoides totais também foram superiores no "Suco-IFFar" em comparação ao suco comercial "Detox", apresentando valores de 18,8 $\mu g \beta$ caroteno g ${ }^{-1}$ e 9,02 $\mu \mathrm{g} \beta$ caroteno $\mathrm{g}^{-1}$, respectivamente (Tabela 1). O teor de carotenoides totais do "Suco-IFFar" também foi superior ao relatado por Fernandes et al. (2007) e Leone (2009), que encontraram teores de $15,01 \mu \mathrm{g} \mathrm{g}^{-1}$ e $6,19 \mu \mathrm{g} \beta$ caroteno $\mathrm{g}^{-1}$, para suco de goiaba e suco misto de frutas e hortaliças, respectivamente.

Quando quantificada a atividade antioxidante dos sucos, utilizando o radical livre ABTS, o suco comercial "Detox" apresentou uma atividade antioxidante de 44,28 $\mu \mathrm{gET} \mathrm{g}^{-1}$, superior ao "Suco-IFFar", que foi de $40,54 \mu \mathrm{gETg}^{-1}$. A atividade antioxidante de frutas e hortaliças tem sido atribuída à atividade de enzimas, como: superóxido desmutase, catalase e peroxidase; de compostos do metabolismo secundário: fenólicos (como ácidos fenólicos, flavonóis, antocianinas) e terpenóides (como carotenos e licopenos), e vitaminas (como C, E e A). Além disso, sabe-se que frações individuais desses compostos podem apresentar atividade antioxidante diferente e que também essas frações podem atuar de forma sinergista, ou seja, podem aumentar a atividade dos antioxidantes em combinações adequada (LIU et al. 2013). Kirakosyan et al. (2010) avaliaram frações de compostos fenólicos extraídos de cereja (Prunus cerasus), individualmente e também em combinações com diferentes concentrações, observando que esses compostos podem atuar em sinergismo, sendo biologicamente mais ativos quando misturados. Dessa forma, atividade antioxidante inferior apresentada pelo "Suco-IFFar" pode estar associada com frações individuais de fenois e carotenoides, ou com a atividade de enzimas antioxidantes ou o teor de vitaminas antioxidantes, que não foram detalhadas nesse estudo.

Foram realizadas análises sensoriais para avaliar a aceitabilidade, a intenção de compra e de comparação entre os sucos "Suco-IFFar" e "Detox". Na análise de aceitabilidade, o índice de aceitabilidade do "Suco-IFFar" foi de 84\%. Quando avaliada a intenção de compra 62\% dos provadores afirmaram que comprariam com frequência o "Suco-IFFar". Já no teste de comparação pareada, comprovou-se que $87 \%$ dos provadores preferiram o "Suco IFFar", quando comparado ao suco "Detox" comercial utilizado.

\section{CONCLUSÃO}

O suco misto elaborado nesse trabalho, denominado "Suco-IFFar", apresentou boa aceitabilidade e intenção de compra. Além disso, o produto apresentou teores significativos de compostos fenólicos e carotenoides, superiores ao apresentado pelo suco comercial "Detox", no entanto uma atividade antioxidante um pouco inferior. 


\section{REFERÊNCIAS}

BRASIL, MINISTÉRIO DA AGRICULTURA, PECUÁRIA E ABASTECIMENTO. Decreto $n^{o}$ 6.871, de 4 de junho de 2009. Brasília, DF, 2009.

BRASIL, MINISTÉRIO DA SAÚDE. Secretária de Vigilância Sanitária. Portaria $n^{\circ} 398$, de 30 de abril de 1999. Brasília, DF, 1999.

BVENURA, C.; SIVAKUMAR, D. The role of wild fruits and vegetables in delivering a balanced and healthy diet. Food Research International, v. 99, p. 15-30, 2017.

ChITARRA, M.I.; CHITARRA, A.B. Pós-colheita de frutos e hortaliças fisiologia e manuseio. Lavras: ESAL/FAEPE, 1990.

COSTA, N. M. B.; ROSA, C. Alimentos funcionais - Componentes Bioativos e Efeitos. Ed. Rubio. Rio de Janeiro, 2010.

DIMITRIUS, B. Sources of natural phenolic antioxidants. Trends in Food Science e Tecnology, v. 17, p. $505-512,2006$.

FERNANDES, A.G.; MAIA, G.A.; SOUZA, P.H.M.; COSTA, J.M.C.; FIGUEIREDO, R.W.; PRADO, G.M. Comparação dos teores em vitamina C, carotenóides totais, antocianinas totais e fenólicos totais do suco tropical de goiaba nas diferentes etapas de produção e influêncua na armazanagem. Alim. Nutr., Araraquara, v.18, p.431-438, 2007.

INSTITUTO ADOLFO LUTZ - IAL. Métodos Físico-químicos para Análise de Alimentos. 4. Ed. São Paulo: IAL. Versão eletrônica, 2008.

KIRAKOSYAN, A.; SEYMOUR, E. M.; NOON, K. R.; LLANES, D. E. U.; KAUFMAN, P. B.; WARBER, S. L.; BOLLING, S. F. Interactions of antioxidants isolated from tart cherry (Prunus cerasus) fruits. Food Chemistry, 2010.

LEONE, R.S. Desenvolvimento de suco misto de frutas e hortaliça para melhoria da qualidade nutricional e funcional (2009). Mestrado em Ciência de Alimentos; Tecnologia de Alimentos; Engenharia de Alimentos. Universidade Federal de Viçosa. Viçosa, $105 \mathrm{f}$.

LIU, R.H. Health-promoting components of fruits and vegetables in the diet. Adv. Nutr.: Int. J. v. 4, p. 384S-392, 2013.

MEDINA, A. L.; HAAS, L. I. R.; CHAVES, F. C.; SALVADOR, M.; ZAMBIAZI, R. C; SILVA, W. P.; NORA, L.; ROMBALDI, C. V. Araçá (Psidium cattleianum Sabine) fruit 
extracts with antioxidant and antimicrobial activities and antiproliferative effect on human cancer cells. Food Chemistry. v. 128, p.916-922, 2011.

MORAES, F. P.; COLLA, L. M. Alimentos funcionais e nutracêuticos: definições, legislação e benefícios à saúde. Revista Eletrônica de Farmácia. v. 3, p. 109-122, 2006.

OETTERER, M.; REGITANO-d'ARCE, M. A. B.; SPOTO, M. H. F. Fundamentos de Ciência e Tecnologia de alimentos. Barueri: Manole, 2006.

RE, R.; PELlEGRINI, N.; PROTEGGENTE, A.; PANNALA, A.; YANG, M.; RICCEVANS, C. Antioxidant activity applying an improved ABTS radical cation de colorization assay. Free Radical Biology and Medicine. v. 26, 1999.

ROBERFROID, M. Functional food concept and its application to prebiotics. Digestive and Liver Disease. v. 34, 2002.

RODRIGUEZ-AMAYA, D. A guide to carotenoids analysis in food. 1. ed. Washington: International Life Sciences Institute Press, 2001.

SILVA, B.V.; BARREIRA, J.C.M.; OLIVEIRA, M.B.P.P. Natural phytochemicals and probiotics as bioactive ingredients for functional foods: Extraction, biochemistry and protected-delivery Technologies. Trends in Food Science \& Technology. v. 50, p.144-158, 2016.

SINGLETON, V.L.; ROSSI, J.A. JR. Colorimetry of total phenolic with phosphomolybdicphosphotungstic acid reagents. American Journal of Enology and Viticulture. v.16, 1965.

STAHL, W.; SIES, H. Antioxidant activity of carotenoids. Molecular Aspects of Medicine. v. 24, p. 345-351, 2003.

SUN, J.; LIU, R.H. Cranberry phytochemical extracts induce cell cycle arrest and apoptosis in human MCF-7 breast cancer cells. Cancer Letters, v. 241, p. 124 - 134, 2006. 